\title{
Electrolytic 'Treatment of Cyanide Wastes VI. Effect of the Bed Height of a Fluidized Bed Electrode Cell on the Electrolytic Oxidation of Cyanide Ion
}

\author{
Morihiro Yasuda *, Akira OHKawa, Masaru Tonsho and Saburo Yasukawa \\ Received October 7, 1988 ; Accepted May 12,1989
}

\begin{abstract}
Electrolytic treatment of dilute cyanide wastes $\left(<0.1 \mathrm{~g} \cdot \mathrm{dm}^{-3} \mathrm{CN}^{-}\right)$was carried out in a fluidized bed electrode (FBE) cell having graphite particles, and the effects of the bed height, $H_{f}$, and the cell current, $I_{c}$, on the direct oxidation of $\mathrm{CN}^{-}$were investigated. With increasing $H_{\mathrm{f}}$ the electrochemically active particle zone became thicker to bring higher current efficiency of $\mathrm{CN}^{-}$-decomposition. The increase in $H_{\mathrm{f}}$ reduced effectively both the time and the electrical energy required to attain the decomposition of $99 \%$. The energy consumption increased almost proportionally to $I_{\mathrm{c}}$.
\end{abstract}

\section{INTRODUCTION}

Previously, we examined factors for the electrolytic detoxication of dilute cyanide wastes $\left.\left(\leqq 0.1 \mathrm{~g} \cdot \mathrm{dm}^{-3}\right) 1 \sim 4\right)$. By using an FBE anode with enlarged effective electrode area ${ }^{3)}$, the waste treatment could be achieved in a short time and with reduced consumption of electrical energy. In an FBE cell, however, there remained a problem that the lower current efficiency was obtained at the larger cell current owing to the localization of the electrochemical reaction zone in the neighborhood of a collector electrode. As an attempt to overcome this problem, the anodic oxidation of chloride ion showing a high current efficiency even at a high current density $5,6^{\prime}$ was applied for the indirect oxidation of $\mathrm{CN}^{-4}$ ). However, this method has also a disadvantage that $\mathrm{Cl}^{-}$, which causes the corrosion of steel, the evolution of $\mathrm{Cl}_{2}$, etc., remains in a treated solution at a high concentration.

Department of Chemical Engineering. Faculty of Engineering, Niigata University (8050 Ikarashi 2-nocho, Niigata, 950-21)

Key Words: Decomposition of Cyanide lon, Anodic Oxidation,: Fluidized Bed Electrode, Electrochemical Activity of Particle
In this study 7 , the effect of the bed height, $H_{\mathrm{f}}$, on the rate of the direct oxidation treatment of $\mathrm{CN}^{-}$in an $\mathrm{FBE}$ cell was investigated.

\section{EXPERIMENTAL}

\subsection{Anodic oxidation of $\mathrm{CN}$ -}

The electrolytic decomposition of $\mathrm{CN}^{-}$to $\mathrm{CNO}^{-}$is shown by Eq. (1).

$$
\begin{aligned}
& \mathrm{CN}^{-}+2 \mathrm{OH}^{-} \rightarrow \mathrm{CNO}^{-}+\mathrm{H}_{2} \mathrm{O}+2 \mathrm{e}^{-} \\
& \mathrm{CNO}^{-}+2 \mathrm{H}_{2} \mathrm{O} \rightarrow \mathrm{NH}_{4}++\mathrm{CO}_{3} 2^{-} \\
& 4 \mathrm{OH}^{-} \rightarrow 2 \mathrm{H}_{2} \mathrm{O}+\mathrm{O}_{2}+4 \mathrm{e}^{-}
\end{aligned}
$$

At $\mathrm{pH} \leqq 10$, formed cyanic acid ion $\mathrm{CNO}^{-}$is decomposed by the reaction (2). Moreover, the oxygen evolution reaction (3) competes with the reaction (1) and lowers the current efficiency of $\mathrm{CN}^{-}$decomposition. In this paper, this current efficiency is reflected on the following decomposition ratio of $\mathrm{CN}^{-}, X$.

$$
X=\left\{\left(C_{0}-C\right) / C_{0}\right\} \times 100 \quad(\%)
$$

where $C_{0}$ and $C$ are the $\mathrm{CN}^{-}$concentrations before and after the electrolysis, respectively.

\subsection{FBE cell}

The concentric cylindrical cell employed was described previously 3). As seen in Fig. 1 , a graphite rod ( $1 \mathrm{~cm}$ in diameter) collector and a stainless steel sheet $(0.35 \mathrm{~mm}$ in 


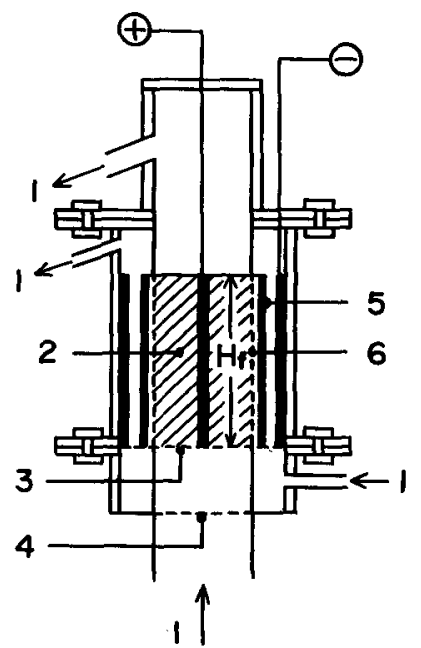

Fig. 1 Concentric cylindrical cell with a fluidized bed anode
1. Electrolyte flow
2. Fluidized bed
3. Distributor
4. Rectifier
5. Diaphragm (anion exchange membrane)
6. Acrylate resin tube
$H_{f}:$ Height of FBE

thickness) counter electrode were located at the center and on the outer cylinder, respectively. 'The height of these electrodes was varied from 10 to $100 \mathrm{~cm}$.

The graphite particles (mean diameter of $1.3 \mathrm{~mm}$, density of $\left.1.7 \times 10^{-3} \mathrm{~g} \cdot \mathrm{dm}^{-3}\right)$ were used as electro-conductive particles. By controlling the amount of graphite particles, the height of a fluidized bed, $H_{\mathrm{f}}$, was varied between 10 and $100 \mathrm{~cm}$. The bed expansion was constant at $20 \%$ at an electrolyte flow rate of $0.042 \mathrm{dm}^{3} \cdot \mathrm{s}^{-1}$ corresponding to a linear velocity of $2.2 \mathrm{~cm} \cdot \mathrm{s}^{-1}$ based on the empty cell3).

\subsection{Electrolyte}

A $10 \mathrm{dm}^{3}$ of $\mathrm{KCN}$ aqueous solution containing $0.1 \mathrm{~g} \cdot \mathrm{dm}^{-3} \mathrm{CN}^{-}$adjusted at $\mathrm{pHI} 11.4$ by $\mathrm{NaOH}$ was flowed through the cell from a bottom at $313 \mathrm{~K}$ and circulated back to the reservoir.

\subsection{Electrolysis}

The electrolysis was carried out at a constant current ranging from 1 to $10 \mathrm{~A}$. The total quantity of electricity was measured by a coulometer. The concentration of $\mathrm{CN}^{-}$was monitored by an ion-selective elec- trode4). 'The adsorption of $\mathrm{CN}^{-}$on graphite could be neglected as in the previous work, and as reported by Yoshizawa et al. ${ }^{8}$.

\section{RESULTS AND DISCUSSION}

\subsection{Decomposition ratio, $X$}

Figures 2 and 3 show the increases in $X$ with the quantity of electricity at two different cell currents, where a broken line corresponds to the theoretical value $(X / \%=100$ at $7417 \mathrm{C}$ ). With increasing $H_{\mathrm{f}}$, the obtained curve approaches gradually to the theoretical line as seen in these figures. 'Thus, the increase in $H_{f}$ raises the current efficiency, because it spreads the effective electrode area and hence reduces a local current density. At $60 \leqq H_{\mathrm{f}} / \mathrm{cm}$, the reaction (1) proceeds almost theoretically up to $X / \%=60$ (Fig. 3) or 80 (Fig. 2), although the loss of current becomes remarkable for further decomposition because of lowered $\mathrm{CN}^{-}$concentration.

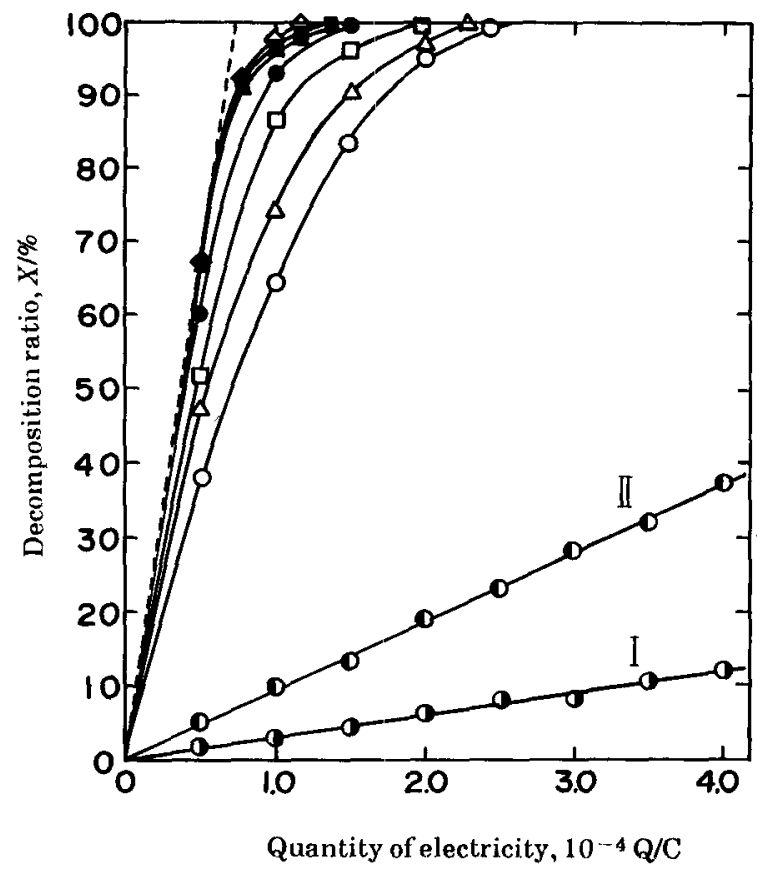

Fig. 2 Decomposition of $\mathrm{CN}^{-}$at the cell current of $2 \mathrm{~A}$ - _ - - - : Theoretical line

Bed height; $O: 10 \mathrm{~cm}, \triangle: 20 \mathrm{~cm}, \square: 30 \mathrm{~cm}$, : $40 \mathrm{~cm}, \triangle: 60 \mathrm{~cm}, \quad 1: 80 \mathrm{~cm}, \diamond: 100 \mathrm{~cm}$ I: empty cell $10 \mathrm{~cm}$, II: empty cell $100 \mathrm{~cm}$ 
The lines I and II in these figures show the results in an empty cell where a collector electrode has the length of 10 and $100 \mathrm{~cm}$, respectively. Though $X$ increases with the length of a collector electrode in an empty cell, it is small compared with those in an FBE cell. This fact reveals that graphite particles act as anode to enlarge effective electrode area.

If we assume that the effective area is proportional to $H_{\mathrm{f}}$, the average current density at $H_{\mathrm{f}}=100 \mathrm{~cm}$ and $I_{\mathrm{c}}=10 \mathrm{~A}$ is equal to that $H_{\mathrm{f}}=20 \mathrm{~cm}$ and $I_{\mathrm{c}}=2 \mathrm{~A}$, and the same value of $X$ will be expected in these two cases. As seen in Figs. 2 and 3 , however, this is not the case which may be ascribed to the phenomenon that the more wide-spread radial distribution of a current density was observed at the smaller cell current, in other words, the electrochemical reaction zone is restricted the more closely to a collector electrode when the larger cell current is applied 3 ). As a conclusion, the increase in $H_{\mathrm{f}}$ lowers the current density on a collector electrode and the active particles, and thereby makes the active particles zone thicker to bring a higher value of $X$.

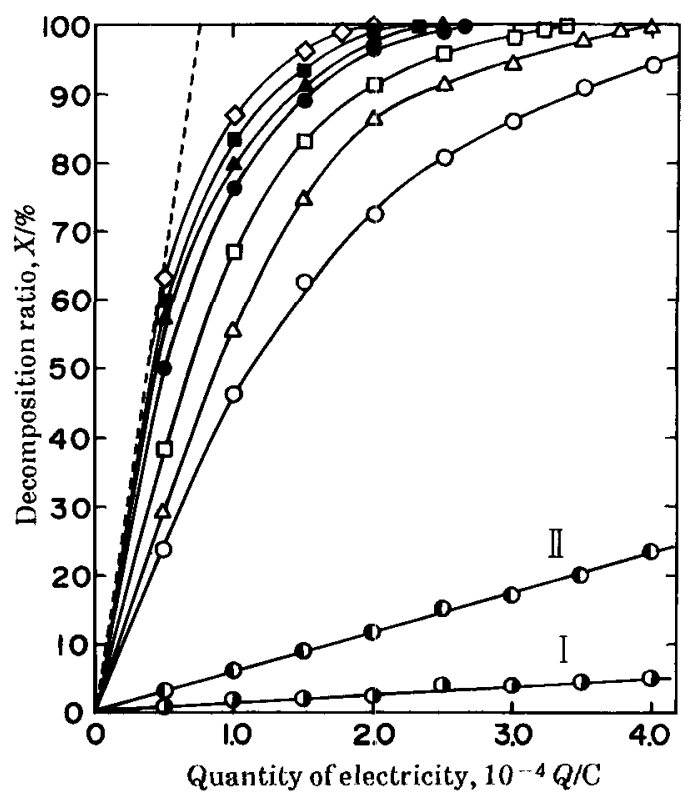

Fig. 3 As Fig. 2 excepting the cell current of $10 \mathrm{~A}$

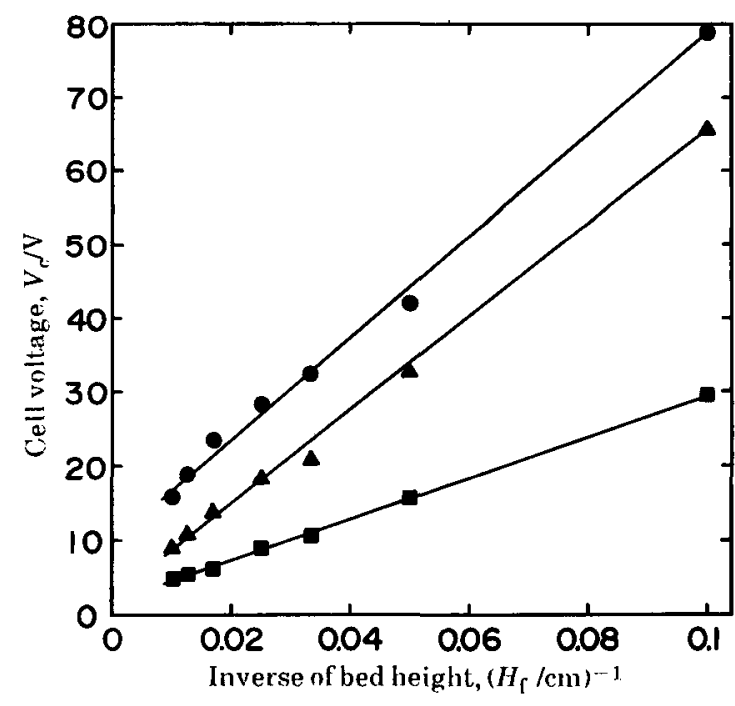

Fig. 4 Relation between the cell voltage and the inverse of a bed height

Cell current;

$: 10 \mathrm{~A}, \quad \Delta: 5 \mathrm{~A}$

$: 2 \mathrm{~A}$

\subsection{Cell voltage, $v_{c}$}

$\Lambda$ s shown in Fig. 4 , the cell voltage, $V_{c}$, decreases linearly with the inverse of $H_{\mathrm{f}}$. 'Thus, the following empirical relationship will hold.

$$
V_{\mathrm{c}}=K / H_{\mathrm{f}}+\text { const. }
$$

where the constant of $K$ depends on the cell current as seen in this figure and presumably also on the electrical resistance of an electrolyte, the bed expansion, the material of particles and electrodes, etc. 'The increase in $H_{\mathrm{f}}$ has a technological merit to reduce $V_{\mathrm{c}}$ as described by Eq. (5).

\subsection{Treatment time, $t_{99}$}

The treatment time, $t_{99}$, defined as the electrolysis time required to decompose $99 \%$ of the initial amount of $\mathrm{CN}^{-}\left(0.1 \mathrm{~g} \cdot \mathrm{dm}^{-3}, 10\right.$ $\mathrm{dm}^{3}$ ), was shown in Fig. 5 as a function of $H_{\mathrm{f}}$. As seen in this figure, $t_{99}$ for each $I_{\mathrm{c}}$ is reduced by about $50 \%$ by the increase in $I_{\mathrm{f}}$ from 10 to $60 \mathrm{~cm}$. At $60 \leqq H_{\mathrm{f}} / \mathrm{cm}, t_{99}$ is shortened slightly with $H_{\mathrm{f}}$. Anyway, it is pointed out that the increase in $H_{\mathrm{f}}$ up to 60 - $80 \mathrm{~cm}$ will be enough to minimize $t_{99}$ effectively. 


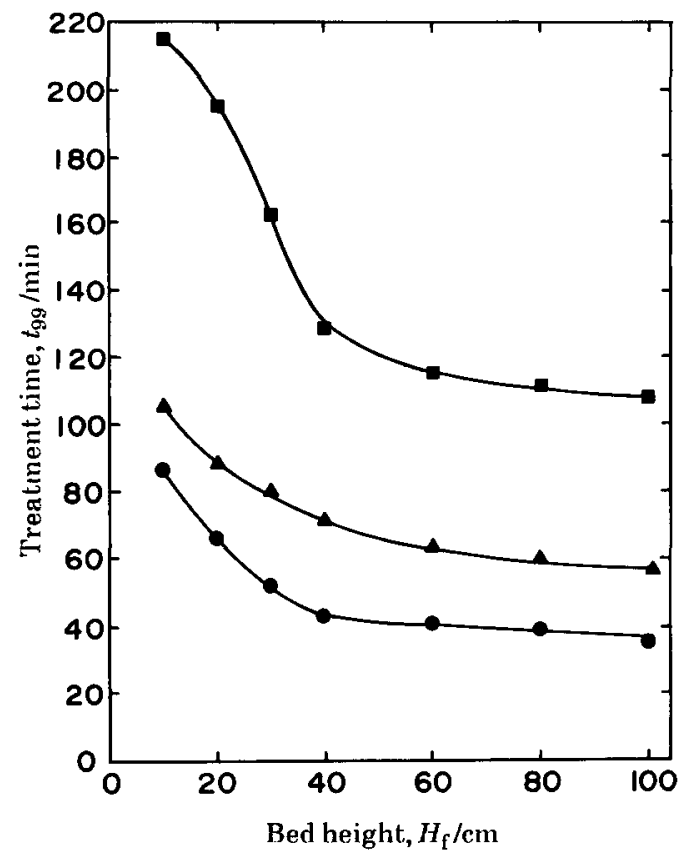

Fig. 5 Relation between the treatment time and a bed height

(keys as in Fig. 4)

\subsection{Energy consumption, E99}

The energy consumption, $E_{99}$, defined as the supplied DC electrical energy to an FBE cell during the period of $t_{99}$, are shown in Fig. 6. As seen in this figure, $E_{99}$ decreases with $H_{\mathrm{f}}$ rapidly at $H_{\mathrm{f}} / \mathrm{cm} \leqq 60$ and slightly at $60 \leqq H_{f} / \mathrm{cm}$. Furthermore, Fig. 7 shows that the following relationship holds empirically.

$$
E_{99} / H_{\mathrm{f}}=1.39 \times 10^{3} I_{\mathrm{c}}{ }^{1.03} H_{\mathrm{f}}{ }^{-2.11}
$$

Rearranging $\mathrm{Eq}$. (6),

$$
E_{99}=1.39 \times 10^{3} I_{c}{ }^{1.03} H_{\mathrm{f}}{ }^{-1.11}
$$

This equation shows that $E_{99}$ is almost proportional to the cell current and to the inverse of a bed height. Eq. (7) is useful to predict the energy consumption in an FBE cell where the particles are dispersed uniformly with the bed expansion of $20 \%$. This equation is useful also to predict $H_{\mathrm{f}}$ for any given $E_{99}$ and $I_{\mathrm{c}}$ at a constant bed expansion of $20 \%$.

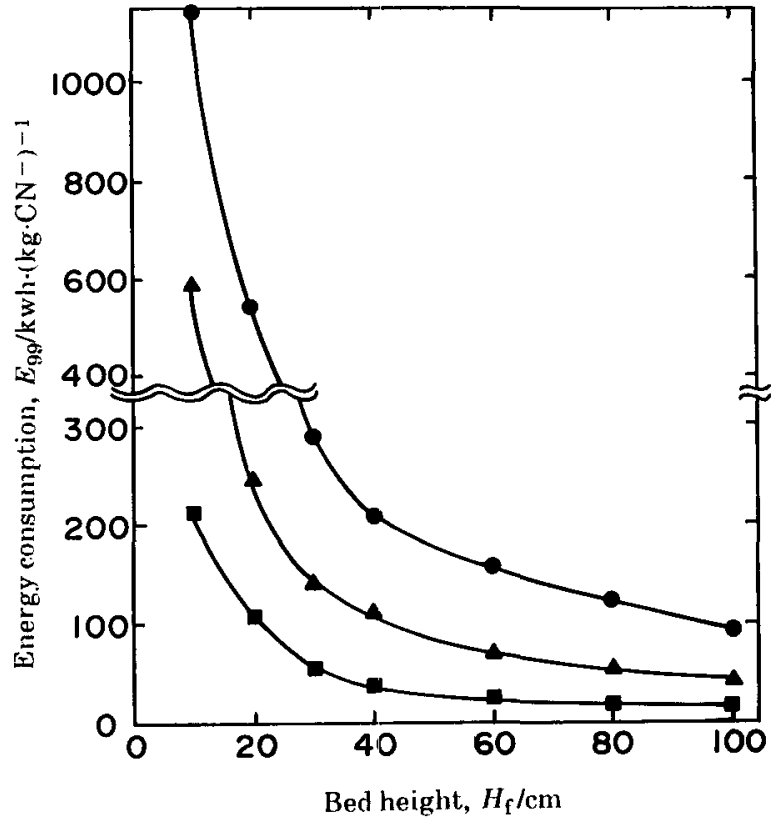

Fig. 6 Relation between the energy consumption and a bed height

(keys as in Fig. 4)

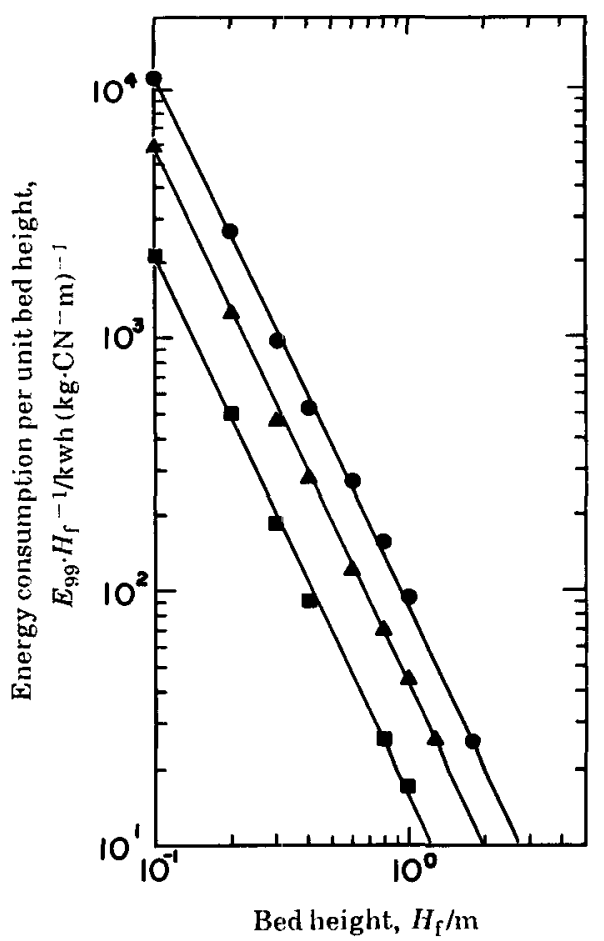

Fig. 7 linearized relation between the energy consumption and a bed height

(keys as in Fig. 4) 


\section{CONCLUSION}

The operation factors for the direct oxidation of dilute cyanide wastes $\left(\leqq 0.1 \mathrm{~g} \cdot \mathrm{dm}^{-3}\right.$ $\mathrm{CN}^{-}$) in an FBE cell were investigated.

1. The increase in a bed height gave technological merits to raise the current efficiency and to reduce the cell voltage.

2. The required $\mathrm{DC}$ electrical energy to reduce $\mathrm{CN}^{-}$down to the level of $1 \mathrm{mg} \cdot \mathrm{dm}^{-3}$ was virtually proportional to the cell current and to the inverse of a bed height.

\section{Acknowledgment}

The authors wish to thank. Asahi Chemical Industry Co., Ltd. for offering anion-exchange membranes.

\section{REFERENCES}

1) M. Yasuda and S. Yasukawa, Denki Kagaku, 52, 491 (1984).

2) M. Yasuda and S. Yasukawa, Denki Kagaku, 52, 744 (1984).

3) M. Yasuda, H. Otake and S. Yasukawa, Denki Kagaku, 54,874(1986).

4) M. Yasuda, S. Yasukawa and M. Inagaki, Denki Kagaku, 55,767 (1987).

5) M.R. Hillis, Trans. $I M F$., 53,65 (1981).

6) V. Ruml and M. Topinka, Metalloberflaeche, 23, 225 (1969).

7) Presented partly at the Meeting of Hokuriku Branch of Electrochem. Soc. of Japan, Toyama, Oct. (1988).

8) S. Yoshizawa, Y. Miyazaki and N. Katagiri, Nippon Kagaku Kaishi, 1, 19 (1977). 